\title{
Non-disclosure of HIV-positive status to a partner and mother-to-child transmission of HIV: Evidence from a case-control study conducted in a rural county in Kenya
}

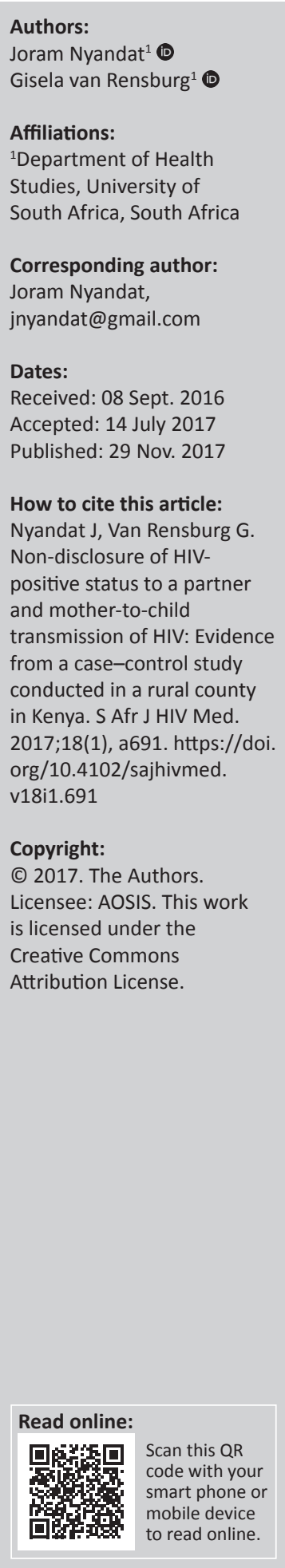

Background: Many factors contribute to an enhanced risk of infant HIV acquisition, two of which may include failure of a mother to disclose her HIV-positive status to her partner and exclusion of male partners in preventing mother-to-child transmission of HIV (PMTCT) interventions. To justify why HIV programmes need to integrate male partner involvement and partner disclosure, we need to establish an association between the two factors and infant HIV acquisition.

Objective: To determine whether failure to disclose an HIV-positive status to a male partner is associated with increased risk of infant HIV acquisition, and whether part of the association is explained by exclusion of male partner in PMTCT programmes.

Methods: Using a case-control study design, we identified a total of 180 mother-baby pairs with HIV-exposed infants. Thirty-six pairs with HIV-positive babies (cases) were compared to 144 pairs with HIV-negative babies (controls) on whether the mothers had disclosed their HIV status to their partner in order to determine whether a disclosure or lack of it contributed to increased risk of mother-to-child transmission of HIV (MTCT). Each case pair was matched to four control pairs from the same facility.

Results: Overall, $16.7 \%$ of mothers had not disclosed their HIV status to their partners, the proportion being significantly more among cases $(52.8 \%$ vs. $7.6 \%, p<0.001)$. Non-disclosure was significantly associated with infant HIV acquisition (aOR $9.8(3.0-26.3) ; p<0.001$ ) and male partner involvement partially mediated the effect of non-disclosure on infant HIV acquisition (indirect coefficient $=0.17, p<0.005$ ).

Conclusions: Failure of an HIV-positive woman to disclose her status to her male partner and exclusion of male partners in PMTCT programmes are two social factors that may curtail success of interventions towards the goal of eliminating MTCT.

\section{Introduction}

Transmission of HIV from the mother to the child (vertical transmission) can occur across the placenta during pregnancy, during the process of delivery and after birth through breast milk. ${ }^{1}$ Breastfeeding and antiretroviral intake modify the risk of vertical transmission. The risk of vertical transmission among mothers not on antiretroviral treatment (ART) in non-breastfeeding population ranges from $15 \%$ to $30 \%$, with the risk being higher among breastfeeding women ( $20 \%$ $-45 \%) .{ }^{2}$ In high-income countries, because of universal access to interventions aimed at preventing mother-to-child transmission of HIV (PMTCT), the risk of vertical transmission has been reduced to less than $1 \% .^{3}$ Globally, PMTCT interventions have resulted in a drastic decline in the incidence of HIV among children. By 2013,58\% fewer children were infected when compared to infection rates in 2002. According to the United Nations Children's Fund (UNICEF) data sheet, ${ }^{4}$ approximately 150000 new HIV infections occurred in 2015, which is a significant improvement from the 2009 statistic of 330000 new infections. However, despite the achievement, the number of new childhood infections is still high considering that PMTCT interventions are universally available. UNICEF ${ }^{4}$ estimates that approximately 6600 children in Kenya were infected with HIV in 2015, representing a mother-to-child transmission of HIV (MTCT) rate of $8 \%$. A study by Nyandiko et al. in 2013 reported MTCT rates of 4\% - 8\% among a population in western Kenya. ${ }^{5}$ A nationwide survey by Kenya National AIDS and STI Control Programme (NASCOP) reported a higher MTCT rate of $16 \%$ among all the infants tested. ${ }^{6}$ The MTCT rates quoted are, however, 
considered to be conservative because of low uptake of Early Infant Diagnosis, estimated to be around $44 \% .{ }^{4}$ The high incidence rate of HIV among children in sub-Saharan Africa has been partly responsible for the reversal of gains witnessed in the past 15 years towards reducing childhood mortality. ${ }^{7}$ More concerted effort is thus required if the goal of eliminating MTCT (EMTCT) is to be realised.

Kenyan PMTCT guidelines (2013) required that any HIV pregnant mother be put on Highly Active Antiretroviral therapy (HAART) during pregnancy irrespective of stage of disease, CD4 count or viral load. On delivery, the infant would receive nevirapine prophylaxis for a period of six weeks. The mother-baby pair was then followed up for a period of 18 months during which the infant would be tested for HIV using DNA polymerase chain reaction (PCR) at six weeks of age, at 9 months and an antibody-based test at 18 months of age. The follow-up of the mother-baby pair was documented in a cohort register called the mother-baby pair register. ${ }^{8}$

While currently, focus has shifted towards addressing psychosocial determinants of vertical transmission, at the beginning of the pandemic when access to antiretroviral drugs was limited, clinical factors were the major risk factors for MTCT. Maternal stage of HIV infection as demonstrated by CD4 count and viral load was majorly responsible for vertical HIV transmission, and undetectable viral load (viral load of $<20$ copies $/ \mathrm{mL}$ ) was protective against MTCT. ${ }^{9}$ Antenatal use of ART reduces risk of vertical transmission of HIV by inhibiting viral replication. ${ }^{10}$ The best route of delivery for prevention of MTCT remains controversial. Caesarean delivery before onset of labour has, however, been shown to present a lower risk of MTCT as compared with vaginal delivery. ${ }^{11}$ Torpey et al. ${ }^{12}$, however, reported that the risk of transmission with vaginal delivery is comparable to that of caesarean delivery if both mother and baby are on ART and prophylaxis respectively. However, the risk increases if invasive intrapartum procedures such as episiotomies are used. ${ }^{13}$ Factors associated with the baby that may increase the risk of acquiring HIV include small for gestational age, low birth weight and failure to receive antiretroviral (ARV) prophylaxis..$^{9,14,15}$

Uptake and utilisation of PMTCT interventions present a proven and effective social strategy for EMTCT, with antenatal HIV counselling and testing, disclosure of HIVpositive status to a partner and inclusion of the male partner underpinning the success of PMTCT interventions in reducing risk of vertical transmission. ${ }^{16}$ In keeping with World Health Organization (WHO) recommendation to routinely test and treat all pregnant women with HIV as part of antenatal care, an increasing number of pregnant women are being tested for HIV. Consequently, a greater number of pregnant women are aware of their HIV status. ${ }^{17}$ In Kenya, awareness of HIV status among pregnant women stands at $66 \%{ }^{18}$ However, the increased awareness of HIV status has not translated into more male partners being disclosed to, more so if the woman is HIV-infected. ${ }^{19,20}$
Several advantages of HIV-positive women disclosing their status have been well described. Disclosure has been shown to increase the level of support towards the pregnant woman, including increased involvement in healthcare processes such as PMTCT interventions. ${ }^{21}$ More specifically, disclosure increases uptake and adherence to antiretroviral drugs (for both mother and baby) for the purpose of PMTCT. ${ }^{21,22}$ This is because HIV-positive pregnant women are at risk of stopping their ARVs to avoid accidental disclosure to the partner. Disclosure also encourages uptake of and adherence to appropriate infant feeding option. In an African set-up, there may be increased pressure by the extended family for early initiation of mixed feeding. Moreover, should the mother prefer formula feeding, the pressure exerted by the family would not make it possible to follow through the option. Disclosure releases the pressure of early mixed feeding. ${ }^{23}$ Finally, women who have disclosed their HIV-positive status to their partners are more likely to deliver at a health facility and will in the process receive appropriate PMTCT interventions. ${ }^{24,25}$

Despite the benefits of disclosure to MTCT, disclosure rates are still low. A systematic review of disclosure rates by Medley et al. ${ }^{26}$ reported varying rates between $16.7 \%$ and $86 \%$. Low disclosure rates have been reported in some parts of Tanzania $(41 \%),{ }^{27}$ Kenya $(49 \%)^{28}$ and Zimbabwe (66\%). ${ }^{29}$ However, disclosure rates were high in Nigeria (90\%), Zimbabwe (97\%) and in Namibia, some parts of Tanzania and Ethiopia $(80 \%) .{ }^{30,31,32}$ Variable rates in disclosure justify focussing on non-disclosure as a key behavioural risk factor for MTCT. ${ }^{33}$

Partner disclosure among women attending antenatal clinics can be promoted by implementing couple testing programmes. Couple testing removes the burden of disclosure on the woman as it encourages mutual disclosure between partners. ${ }^{34,35}$ Other factors positively correlated with disclosure include status of relationship, with married women in a stable relationship being more likely to disclose. ${ }^{36,37}$ Awareness of partners' HIV status also reduces chances of disclosing one's own status by $98 \% .{ }^{38}$ Additionally, younger women with no children and more educated women are less likely to disclose..$^{27,38,39}$ Finally, a woman on antiretroviral medicines is more likely to have disclosed her status as pre-treatment counselling emphasises disclosure as part of adherence counselling. ${ }^{40}$

Limited studies have been conducted to evaluate how non-disclosure to a male partner affects risk of MTCT. Moreover, results reported have been contradictory. $21,22,28,41$ This study was based on the background of these inconsistent findings and on the scarcity of studies on the association between non-disclosure of HIV-positive status to partners and MTCT. We therefore sought to examine the relationship between non-disclosure of an HIV-positive status to a partner and infant HIV acquisition. Further to finding an association we sought to determine whether the effect of non-disclosure on MTCT is partially related to male partner involvement. 


\section{Materials and methods Study design}

Using a case-control study design, we identified a total of 180 mother-baby pairs with HIV-exposed infants (HEIs). Thirtysix pairs with HIV-positive babies (cases) were compared to 144 pairs with HIV-negative babies (controls) on whether the mothers had disclosed their HIV status to their partner (exposure) in order to determine whether disclosure or lack of it contributed to increased risk of MTCT. Each case pair was matched to four control pairs from the same facility.

\section{Study setting}

The study was conducted in Siaya County, Kenya. Siaya County, one of the 47 counties in Kenya, is located in western Kenya, to the east of Lake Victoria. The county has six sub-counties, and as of 2016, had an estimated population of 932,754 . Approximately $54 \%$ are females $(500,889)$ and has one of the highest HIV prevalence rates in Kenya at $24.8 \%$, and an equally high MTCT rate of $21 \% .^{42}$ Similarly, the high childhood mortality rates (partly attributed to HIVrelated complications and malnutrition) of 39/1000, 111/1000 and $159 / 1000$ for neonatal mortality rate, infant mortality rate and under five mortality rates respectively are some of the highest in Kenya.

The public health system in Kenya follows a hierarchical pyramidal structure with four levels (also called tiers) of service delivery. Community units form the lowest level of service delivery (tier 1), focussing on the promotion of appropriate healthy behaviours. This level has no physical structures. Above this level are primary care facilities (dispensaries, health centres, clinics and maternity homes) whose focus is on disease prevention and health promotion services. County referral hospitals (tier 3 ) encompass county and sub-county referral facilities. Tier 3 facilities not only provide comprehensive in-patient diagnostic, medical, surgical and rehabilitative care, but also facilitates referrals to the National Hospitals, which form the highest level of health service delivery in the county (tier 4$){ }^{42}$

The highest level of care in the county is provided by the County Referral Hospital. Siaya County has three tier 3 health facilities and 154 tier 2 health facilities. ${ }^{42}$ Participants for the study were enrolled from the County Referral Hospital and the five sub-county referral hospitals (Tier 3 facilities). The selection was based on the fact that tier 1 and 2 facilities do not normally conduct deliveries. Sub-county and the county referral hospitals deliver more than $95 \%$ of babies in the county, the remaining $5 \%$ being handled by health centres and private facilities in the county. ${ }^{42}$

\section{Participants}

The target population for this study was HIV-positive mothers and their infants (referred to in this study as a mother-baby pair). A mother-baby pair being cared for at a health facility in Siaya County became eligible for enrolment into the study. Additionally, the infant in the pair should have been born between January 2013 and June 2014 in any of the five sub-county and one county referral hospitals.

To identify eligible mother-baby pairs, we reviewed the mother-baby pair HIV cohort registers provided by the Ministry of Health to all health facilities providing PMTCT services. Identified HIV-positive mother-baby pairs provided the sampling frame. Incidence density sampling was used in the selection of cases, and Simple random sampling was used to select 'potential' controls from the sampling frame. We aimed to select four controls for every case identified. A case was identified as an HIV-positive mother-baby pair with an infant who tested HIV-positive at six weeks of age and since cases were newly diagnosed, they represented incident cases for the study period. A control was an HIV-positive motherbaby pair with an infant who was HIV-negative at six weeks. Controls were individually matched to cases by the health facility. We excluded from the study mother-baby pairs with mothers who were not in a sexual relationship during the pregnancy and postnatal period.

Health facilities within the county serve a defined geographic region with a specific catchment population. The population differs on economic status, facility-population ratio, customs and traditions, and health-seeking behaviours. Moreover, health facilities vary in terms of standards of care, drug stock outs (in reference to ARVs) and practices. All these factors are likely to affect disclosure as well as MTCT. Therefore to control for these variables a priori, we matched one case to four controls in a given facility.

\section{Variables}

Included in this analysis were mother-baby pairs composed of HEIs and their mothers. The definition of HEI was adopted from the Ministry of Health, Kenya, which defines an HEI as a child (who is less than 18 months old) born to an HIV-positive mother. In this study, any mother with an HIV-positive status, as recorded in the HEI facility, book was taken to be HIVpositive. Our exposure variable was non-disclosure of HIV status to a partner, which in this study was defined as failure by an HIV-positive mother to disclose her positive status to her partner prior to learning the infant's HIV status. Mothers were asked whether they had disclosed to their male partners prior to knowing the 6-week test outcome done at the health facility. The test is usually undertaken during the first immunisation schedule, and this was used as an 'aide de memoire'. A male partner was defined as presence of a male figure in the life of the baby with whom the mother was having a sexual relationship prior to knowing the HIV status of the baby. Male partner involvement was defined as male partner accompanying the woman to the hospital at any time during the pregnancy, delivery and 6-week immunisation visit.

Non-disclosure of HIV-positive status to male partner was hypothesised to contribute to the risk of infant HIV acquisition. We further hypothesised that male partner involvement is partially responsible for the observed effect of 
non-disclosure on infant HIV acquisition by determining uptake of PMTCT interventions such as hospital visits for PMTCT, uptake of ART and infant prophylaxis and adherence to safe feeding option for the infant. These variables were considered to be in the causal pathway as illustrated in Figure 1. In the statistical analyses, factors considered potential confounders and not matched for were couple testing, disclosure to others, length of relationship with partner and number of antenatal visits.

\section{Data source and measurement}

The county's HIV-positive mother-baby pair register was used to identify HIV-positive mother-baby pairs receiving care at the health facility. The 6-week HIV PCR result, also documented in the mother-baby pair register, was used to classify the mother-baby pairs into cases (mother-baby pair with an infant whose 6-week HIV PCR test was positive) or controls (mother-baby pair with an infant whose 6-week HIV PCR test was negative). We then retrieved the medical records of the potential respondents (defined as mothers in the mother-baby pair), which allowed us to contact potential respondents, describe the purpose of the study and request them to consider being part of the study. Mothers who showed willingness to be included in the study were enrolled and presented with questionnaire during their next routine clinical visit. During the visit, the aim of the study was explained to the mothers again, after which a signed written consent was obtained before the mothers were given the questionnaire to complete. The researcher was at hand to clarify and guide the respondents when required. The questionnaire extracted information related to mother's personal details, status of disclosure to the partner or others, couple testing, awareness of HIV status of the partner and the length of relationship. Male partner involvement was considered by collecting information on accompaniment by the partner to the clinic during pregnancy and after delivery, and couple testing.

\section{Bias}

Threats to validity were well anticipated and addressed. Selection bias was minimised by using results from PCR test which has a high sensitivity ( $100 \%$ at one month of age) and specificity ( $99.8 \%$ at birth and $100 \%$ at one month of age). ${ }^{43}$ Recall bias because of likelihood of cases remembering exposures to risk factors more than controls was minimised by limiting the time period of exposure to less than two years. The questionnaire was self-administered, minimising risk of bias from data collectors. ${ }^{44}$

\section{Sample size}

The study required a sample size of 34 case-control sets. Using a difference in proportions formula for matched casecontrol studies, ${ }^{45}$ we assumed a mean proportion of nondisclosure of $40 \%$ and $15 \%$ in case and control respectively, an odds ratio of two for a case-control matched ratio of 1:4, a power of $80 \%$ and significance level of $5 \%$.

\section{Statistical methods}

Normality was assessed visually using box-plots and statistically using Shapiro-Wilk's test $(p<0.05) .{ }^{46}$ To determine whether there were differences between case and control groups with regard to study variables, we employed student's $t$-test for continuous data and chi-square test for categorical data as required. The odds ratio, $95 \%$ confidence intervals and

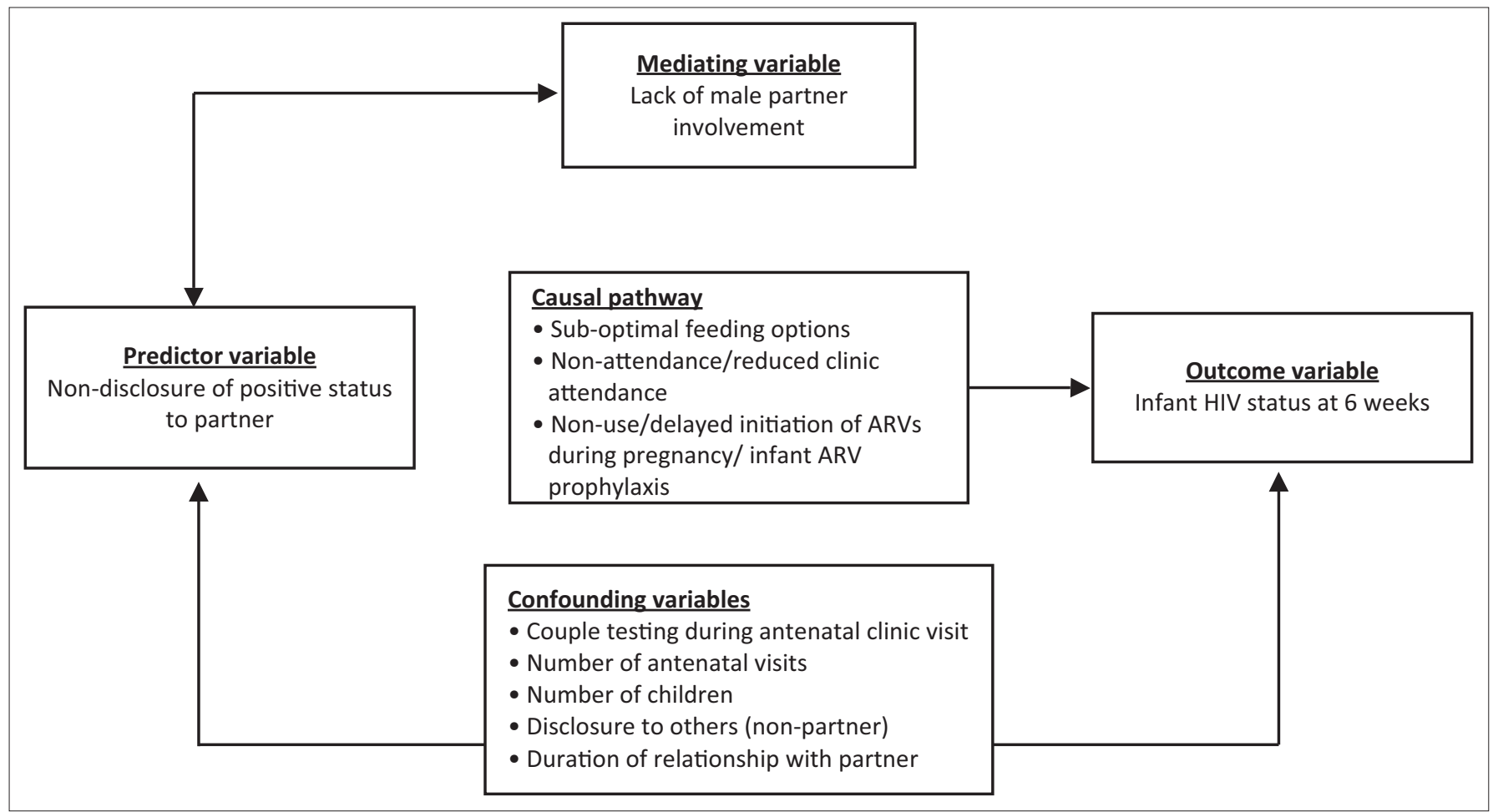

FIGURE 1: Conceptual framework for relationship among variables affecting non-disclosure and mother-to-child transmission of HIV. 
significance level of the matched-pair data were calculated using Mantel-Haenszel statistical test. The significance level was set at $p<0.05$. Variables which were significant in bivariate analysis and not in the causal pathway were controlled for in the multivariable analysis using conditional logistic regression.

To determine mediation, we performed four regression analyses as illustrated in Figure 2. The first analysis assessed whether non-disclosure (independent variable) is significantly associated with MTCT (dependent variable). This analysis is illustrated in the diagram as path c. The second analysis assessed whether non-disclosure was significantly associated with male partner involvement (mediator variable) illustrated in the diagram as path a. The third analysis assessed whether male partner involvement is associated with MTCT (dependent variable) illustrated as path b. Finally, to determine partial versus full mediator effect, we controlled for the effect of male partner involvement on MTCT illustrated as path $\mathrm{c}^{\prime} .^{47}$

Statistical Package for Social Sciences (SPSS) version 22.0 for Windows was used for analysis. STATA v12 and MPLUS (Version 6.11) were used for matched analysis, and significance of the mediation tested using the Sobel test. ${ }^{48}$

\section{Ethical consideration}

Ethical and administrative approval of the study methodology was granted by the Research and Ethics Committee, Department of Health Studies, UNISA, on 29 October 2013 and local ethical approval obtained from Moi University, College of Health Sciences Research and Ethics Committee on 03 March 2014. Permission to conduct the study in Siaya County was sought and granted by the County Director of Health. All facilities received a copy of the research proposal and copies of the ethical clearance certificates together with the request for permission to conduct the study at the institution. Additional verbal permission was obtained from the in-charges of the various health facilities. Written, informed consent was obtained from each participant prior to the interviews.

\section{Results}

\section{Response rate}

The response rate of $72 \%$ was deemed adequate as it represented the minimum sample size required to achieve

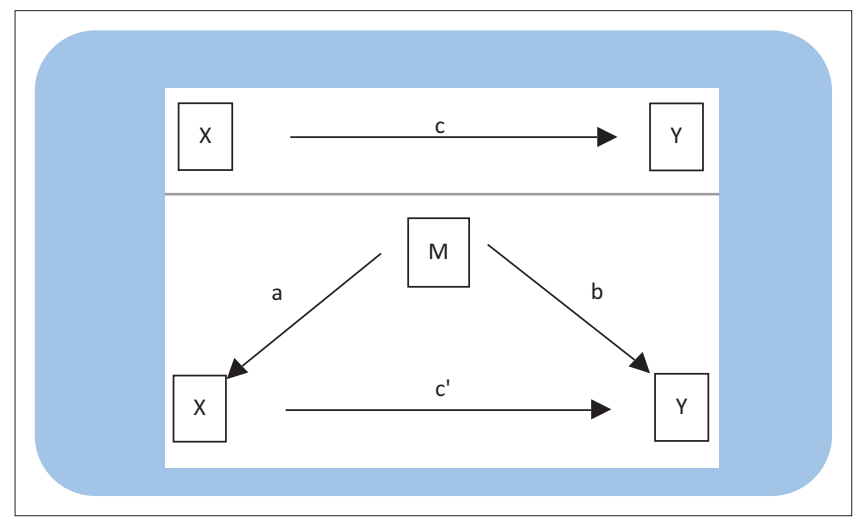

FIGURE 2: Framework for mediation analysis ${ }^{47}$. an $80 \%$ power. ${ }^{49,50}$ Fifty three cases and 205 controls were identified in the study, of which 36 cases and 144 controls were enrolled in the study (Figure 3 ). The main reasons for non-participation were relocation (cases 32\%, controls $<18 \%$ ), infants aged more than six months (cases 35\%, controls 61\%) and mother not in any relationship (cases $18 \%$, controls $9 \%$ ). Other reasons included death of infants (17\% cases) and lack of PCR result in register (control 14\%). There was no missing information as we ensured completeness of the filled questionnaire. We compared mother-baby pairs not enrolled to the study to those enrolled in the study with regard to three variables (age of mother, birth weight of infant, HIV disclosure) to determine whether the two groups differed on the selected variables. (Table 1) The information for non-enrolled pairs was obtained from the mother-baby pair cohort register. A twotailed, two-sample $t$-test was used to compare mother's mean age and child's birth weight, and chi-square test was used to compare disclosure status. As shown in Table 1, the differences were not statistically significant at the 0.05 level of significance. Therefore, we were confident of minimal error of effect measures obtained from the study. ${ }^{51}$

\section{Descriptive statistics}

Overall, $43 \%(n=78)$ of the infants in the mother-baby pairs were female and the median (IQR) age was 10 (7) months. The mean (SD) birth weight was $3.2(0.6) \mathrm{kg}$ and the mean (SD) maternal age was 27.4 (5.4). Sixty-six per cent $(n=119)$ of mothers were in monogamous relationship compared to $24 \%$ $(n=29)$ in a polygamous relationship. Most mothers $(78.3 \%)$ had primary school education, with $21.6 \%(n=39)$ having obtained post-primary school education.

\section{Non-disclosure and mother-to-child transmission of HIV}

Approximately $17 \%(n=30)$ of mothers in the mother-baby pairs had not disclosed their HIV-positive status to their partners. A significantly higher proportion of cases had not disclosed their HIV status $(52.8 \%$ vs. $7.6 \%$; OR $=11.8$ [4.5-30.8]). Four variables were significantly found to be associated with MTCT. Infant prophylaxis and absolute breastfeeding were significantly associated with MTCT $(\mathrm{OR}=0.12[0-0.9])$ and $0.19(0.07-0.48)$, respectively. Involvement of the male partner and awareness of HIV status of the partner were also associated with infant HIV acquisition $(\mathrm{OR}=0.30[0.10-0.50]$ and $\mathrm{OR}=0.12[0.1-0.90])$ (Table 2). Awareness of male partner status was the only variable significantly associated with infant HIV acquisition and not in the causal pathway. During multivariable analysis, even after controlling for awareness of male partner HIV status, non-disclosure of HIV-positive status to a partner maintained its significance as a risk factor for MTCT aOR 9.8 (95\% CI 3.0-26.3) (Table 3).

For mediation analysis, path c regression coefficient illustrated that non-disclosure was significantly associated to MTCT $(0.37, p<0.001)$, satisfying the first condition for mediation (Figure 4). Similarly, path a and path b regression 


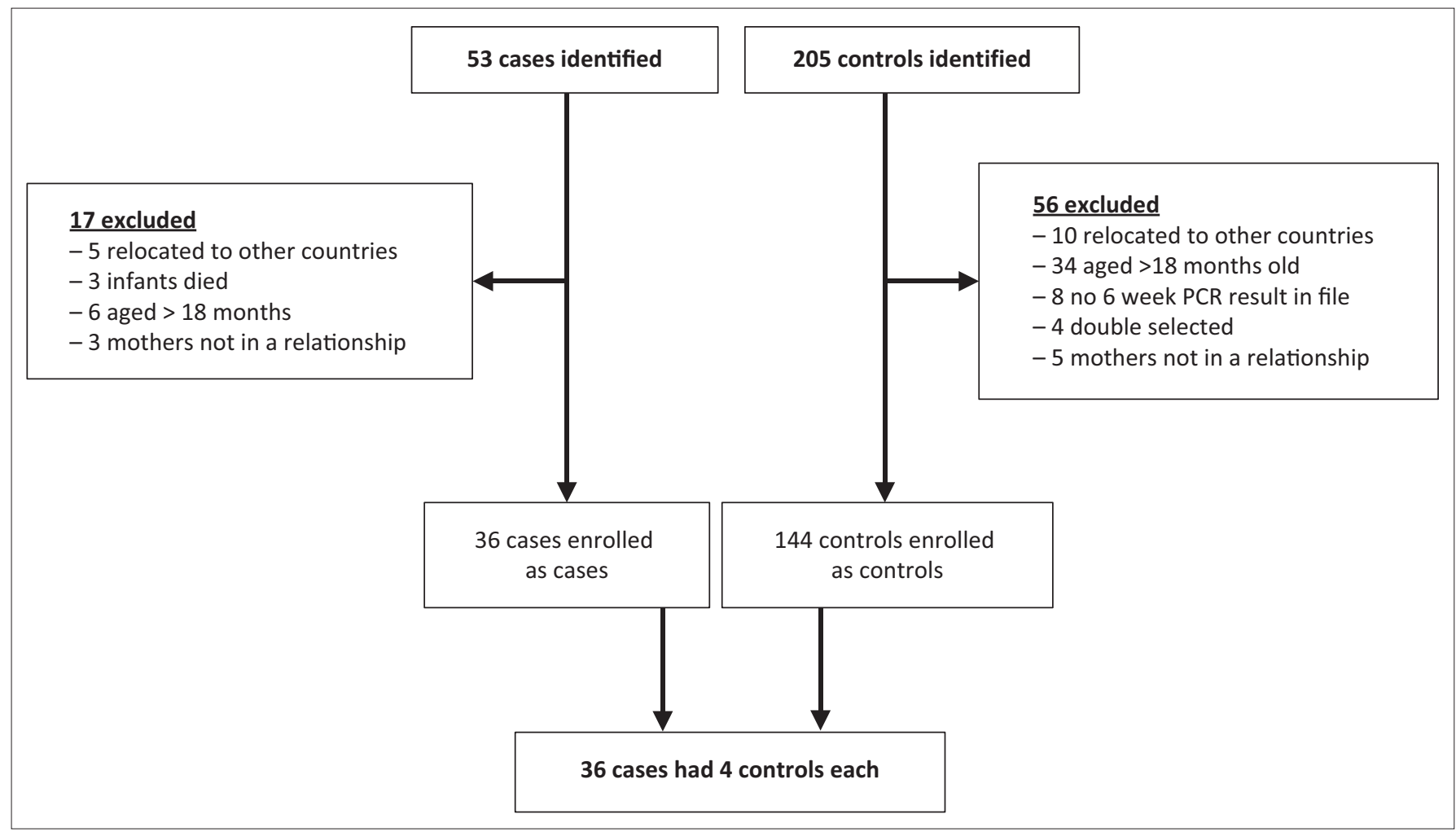

FIGURE 3: Summary of inclusion and exclusion of participants.

TABLE 1: Differences in characteristics of respondents versus non-respondents.

\begin{tabular}{|c|c|c|c|c|c|c|c|c|c|}
\hline \multirow[t]{2}{*}{ Variable } & \multicolumn{4}{|c|}{ Respondents $(n=180)$} & \multicolumn{4}{|c|}{ Non-respondents $(n=78)$} & \multirow[t]{2}{*}{$p$} \\
\hline & $N$ & $\%$ & Mean & SD & $N$ & $\%$ & Mean & SD & \\
\hline Mother's age (years) & - & - & 27.4 & 5.4 & - & - & 26.9 & 4.2 & 0.327 \\
\hline Child's birth weight (kg) & - & - & 3.2 & 0.6 & - & - & 2.9 & 1.3 & 0.289 \\
\hline Disclosure statust (yes) & 150 & 83.0 & - & - & 55 & 78.0 & - & - & 0.642 \\
\hline
\end{tabular}

$\dagger$, Disclosure status for non-respondents was obtained from medical records at the facility.

coefficients were significantly related $(0.51, p<0.001$ and $0.36, p<0.001)$ satisfying the second and third conditions for mediation respectively. The indirect effect (path $c^{\prime}$ ) suggested partial mediation of male partner involvement on the association between non-disclosure and MTCT as the coefficient was substantially reduced $(0.17, p=0.01)$ compared to the direct effect coefficient of 0.37 .

\section{Discussion}

Two significant findings have emerged from this research effort. First is that infants born to HIV-positive mothers are more likely to become HIV-positive if they have a mother who has failed to disclose her HIV-positive status, and second is that the association between non-disclosure and infant HIV acquisition is partly because of the effect of male partner involvement.

Approximately $83.3 \%$ of HIV-positive mothers enrolled in the study reported having disclosed to their partner. This proportion is comparable to most reports from sub-Saharan Africa, with disclosure proportions between $16.7 \%$ and $86 \%{ }^{26}$ Bachanas et al. ${ }^{19}$ reported $80 \%$ of the 3538 HIV-positive patients in Kenya, Tanzania and Botswana had disclosed their status to their partners. Similarly, 70\% of $20 \mathrm{HIV}$-positive pregnant women in Kenya had disclosed their status. ${ }^{52}$ The rate of HIV status disclosure in this study is considered to be conservative. Similar to other similar studies, status of disclosure is based on self-report which raises the possibility of social desirability bias. To minimise reports of disclosure while it did not happen, the researcher did not emphasise any question during data collection to ensure that respondents did not feel some of the questions were more important. We also corroborated the responses obtained from the respondents with the disclosure status documented in the patient's file. Where there was discordance or when no response was recorded, the mother was contacted to clarify the true position.

One finding unique to this study relates to the significantly higher proportion of HIV-positive infants having mothers who have not disclosed their positive status to their partners. Approximately $52 \%$ had not disclosed their status, compared to only $7.6 \%$ among mothers with HIV-negative infants (OR $=11.8$ [95\% CI 4.5-30.9]). The significance of the association was not altered even after controlling for awareness of partner status.

A mother's decision against disclosing her HIV-positive status to her partner may be motivated by several factors. Central is the ability to overcome difficulty associated with 
TABLE 2: Comparison of variables between cases and controls.

\begin{tabular}{|c|c|c|c|c|c|c|c|c|c|c|}
\hline \multirow[t]{2}{*}{ Variable } & \multirow[t]{2}{*}{ Category } & \multicolumn{2}{|c|}{ Total } & \multicolumn{2}{|c|}{ Case } & \multicolumn{2}{|c|}{ Control } & \multirow[t]{2}{*}{ OR } & \multirow[t]{2}{*}{$95 \% \mathrm{Cl}$} & \multirow[t]{2}{*}{$p$} \\
\hline & & $n$ & $\%$ & $n$ & $\%$ & $n$ & $\%$ & & & \\
\hline \multirow{4}{*}{$\begin{array}{l}\text { Marital } \\
\text { status }\end{array}$} & Unmarried & 18 & 10 & 5 & 13.2 & 13 & 9.2 & - & - & 0.45 \\
\hline & Married, monogamy & 119 & 66 & 28 & 73.7 & 91 & 64.1 & & & \\
\hline & Married, polygamy & 29 & 16 & 4 & 10.5 & 25 & 17.6 & & & \\
\hline & Divorced or widowed & 14 & 7.8 & 1 & 2.6 & 13 & 9.1 & & & \\
\hline \multirow{2}{*}{$\begin{array}{l}\text { Educational } \\
\text { level }\end{array}$} & Basic & 141 & 78.3 & 31 & 81.6 & 110 & 77.5 & - & - & 0.64 \\
\hline & Post-primary & 39 & 21.6 & 7 & 18.4 & 32 & 22.5 & & & \\
\hline \multirow[t]{2}{*}{ Age of child } & $<6$ months & 39 & 21.7 & 11 & 28.9 & 28 & 19.7 & - & - & 0.22 \\
\hline & $>6$ months & 141 & 78.3 & 27 & 71.1 & 114 & 80.3 & & & \\
\hline \multirow[t]{2}{*}{ Mother's age } & $<25$ & 59 & 32.8 & 16 & $42.1 \%$ & 43 & 30.3 & - & - & 0.11 \\
\hline & $>25$ & 121 & 67.2 & 22 & 57.9 & 99 & 69.7 & & & \\
\hline \multirow{2}{*}{$\begin{array}{l}\text { Infant } \\
\text { prophylaxis }\end{array}$} & Yes & 174 & 96.7 & 34 & 89.5 & 140 & 98.6 & 0.12 & $0-0.90$ & $0.005^{*}$ \\
\hline & No & 6 & 3.3 & 4 & 10.5 & 2 & 1.4 & & & \\
\hline \multirow{2}{*}{$\begin{array}{l}\text { Place of } \\
\text { birth }\end{array}$} & Health facility & 150 & 83.3 & 30 & 78.9 & 120 & 84.5 & 0.60 & $0.30-1.60$ & 0.35 \\
\hline & Home & 30 & 16.7 & 8 & 21.2 & 22 & 15.5 & & & \\
\hline \multirow{2}{*}{$\begin{array}{l}\text { Type of } \\
\text { feeding }\end{array}$} & Breastfeeding & 158 & 87.8 & 26 & 68.4 & 132 & 93.0 & 0.19 & $0.07-0.48$ & $<0.001 *$ \\
\hline & Mixed feeding & 22 & 12.2 & 12 & 31.6 & 10 & 7.0 & & & \\
\hline \multirow{2}{*}{$\begin{array}{l}\text { Mode of } \\
\text { delivery }\end{array}$} & No procedure & 172 & 95.6 & 38 & 100 & 134 & 94.4 & - & - & 0.35 \\
\hline & Procedure & 8 & 4.4 & 0 & 0 & 8 & 5.6 & & & \\
\hline \multirow{2}{*}{$\begin{array}{l}\text { Antenatal clinic } \\
\text { attendance }\end{array}$} & Yes & 179 & 99.4 & 38 & 100 & 141 & 99.3 & - & - & 0.80 \\
\hline & No & 1 & 0.6 & 0 & 0 & 1 & 0.7 & & & \\
\hline \multirow{2}{*}{$\begin{array}{l}\text { Partner } \\
\text { involvement }\end{array}$} & Yes & 33 & 18.3 & 4 & 10.5 & 29 & 20.4 & 0.12 & $0.10-0.90$ & $<0.001 *$ \\
\hline & No & 147 & 81.7 & 34 & 89.5 & 113 & 79.6 & & & \\
\hline \multirow{2}{*}{$\begin{array}{l}\text { Maternal } \\
\text { prophylaxis }\end{array}$} & Yes & 165 & 91.7 & 32 & 84.2 & 133 & 93.7 & 0.39 & $0.13-1.19$ & 0.09 \\
\hline & No & 15 & 8.3 & 6 & 15.8 & 9 & 6.3 & & & \\
\hline \multirow{2}{*}{$\begin{array}{l}\text { Duration aware } \\
\text { of status }\end{array}$} & $<1$ year & 55 & 30.6 & 9 & 23.7 & 46 & 32.4 & 0.7 & $0.3-1.7$ & 0.425 \\
\hline & $>1$ year & 125 & 69.4 & 29 & 76.3 & 96 & 67.6 & & & \\
\hline \multirow{2}{*}{$\begin{array}{l}\text { Duration of } \\
\text { relationship } \\
\text { with partner }\end{array}$} & $<1$ year & 156 & 86.6 & 32 & 83.8 & 124 & 87.3 & 0.8 & $0.2-2.3$ & 0.713 \\
\hline & $>1$ year & 24 & 13.4 & 6 & 16.2 & 18 & 12.7 & & & \\
\hline \multirow{2}{*}{$\begin{array}{l}\text { Time of } \\
\text { disclosure }\end{array}$} & Before pregnancy & 143 & 93.5 & 18 & 85.7 & 125 & 94.7 & 0.2 & $0.1-1.4$ & 0.112 \\
\hline & After pregnancy & 10 & 6.5 & 3 & 14.3 & 7 & 5.3 & & & \\
\hline Time to & $<3$ months & 116 & 75.8 & 17 & 85 & 99 & 77.4 & 1 & $0.2-4.0$ & 1.000 \\
\hline & $>3$ months & 37 & 24.2 & 3 & 15 & 34 & 25.6 & & & \\
\hline Awareness of & Yes & 109 & 60.6 & 14 & 36.8 & 95 & 66.9 & 0.3 & $0.1-0.5$ & $<0.001^{*}$ \\
\hline & No & 71 & 39.4 & 24 & 63.2 & 47 & 33.1 & & & \\
\hline Tested as a & Yes & 43 & 23.9 & 6 & 15.8 & 37 & 26.1 & 0.56 & $0.23-1.36$ & 0.201 \\
\hline & No & 137 & 76.1 & 32 & 84.2 & 105 & 73.9 & & & \\
\hline Disclosed to & Yes & 135 & 75.0 & 27 & 71.1 & 108 & 76.1 & 0.8 & $0.3-1.7$ & 0.528 \\
\hline & No & 45 & 25 & 11 & 28.9 & 34 & 23.9 & & & \\
\hline & Yes & 167 & 92.8 & 36 & 94.7 & 131 & 92.3 & 1.7 & $0.3-8.0$ & 0.494 \\
\hline $\begin{array}{l}\text { disclose by } \\
\text { health worker }\end{array}$ & No & 13 & 7.2 & 2 & 5.3 & 11 & 7.7 & & & \\
\hline Follow-up on & Yes & 160 & 88.9 & 33 & 86.8 & 127 & 89.4 & 0.9 & $0.2-2.7$ & 0.809 \\
\hline disclosure & No & 20 & 11.1 & 5 & 13.2 & 15 & 10.6 & & & \\
\hline
\end{tabular}

$\mathrm{OR}$, odds ratio; $\mathrm{Cl}$, confidence interval.

$*, p=0.05$.

TABLE 3: Bivariable and multivariable analysis of non-disclosure of HIV-positive status among cases and controls.

\begin{tabular}{|c|c|c|c|c|c|c|c|c|c|c|c|c|c|c|c|c|c|c|}
\hline \multirow[t]{2}{*}{ Cases } & \multicolumn{3}{|c|}{ Control 1} & \multicolumn{3}{|c|}{ Control 2} & \multicolumn{3}{|c|}{ Control 3} & \multicolumn{3}{|c|}{ Control 4} & \multirow[t]{2}{*}{ UOR } & \multirow[t]{2}{*}{$\mathrm{Cl}$} & \multirow[t]{2}{*}{$p$} & \multirow[t]{2}{*}{ AOR } & \multirow[t]{2}{*}{$\mathrm{Cl}_{\dagger}$} & \multirow[t]{2}{*}{$p$} \\
\hline & + & - & $T$ & + & - & $T$ & + & - & $T$ & + & - & $T$ & & & & & & \\
\hline Exposed & 1 & 18 & 19 & 0 & 19 & 19 & 1 & 18 & 19 & 1 & 16 & 17 & 11.8 & $4.5-30.8$ & $<0.001$ & 9.8 & $3.0-26.3$ & $<0.001$ \\
\hline Unexposed & 4 & 13 & 17 & 4 & 16 & 20 & 2 & 15 & 17 & 0 & 17 & 17 & & & & & & \\
\hline Total & 5 & 31 & 36 & 4 & 35 & 39 & 3 & 33 & 36 & 1 & 33 & 34 & - & - & - & - & - & - \\
\hline
\end{tabular}

UOR, unadjusted odds ratio; $\mathrm{AOR}$, adjusted odds ratio; $\mathrm{Cl}$, confidence interval; $\mathrm{T}$, total +, exposed; -, unexposed.

$\dagger$, Adjusted for awareness of male partner HIV status.

fear of abandonment, accusation of infidelity, discrimination, violence and loss of spousal financial support. ${ }^{35,53}$ The fears experienced by the mothers are justified. Farquhar et al. ${ }^{35}$ reported that women who work away from home or who are more sexually experienced fear disclosure because of the belief that they will be blamed for infidelity. Women who had previously experienced violence were less likely to disclose their HIV status to their partners. ${ }^{26}$ Disclosure is also influenced by the nature of the couple's relationship, such that disclosure may only be a pointer to the state of the relationship. Married women and partners who have good communication, for example, couples who discussed HIV 


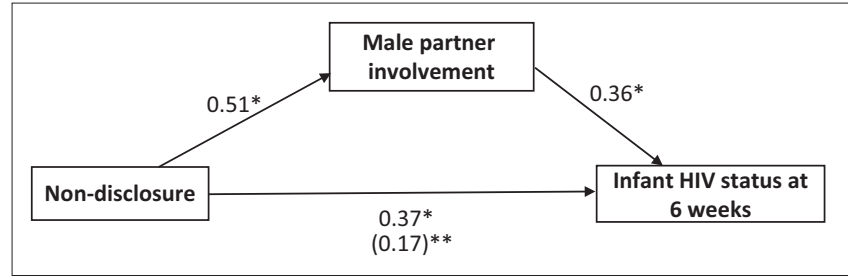

$*, p<0.001 ; * *, p<0.01$.

FIGURE 4: Regression coefficients for relationship between non-disclosure and HIV status at 6 weeks as mediated by male partner involvement.

testing prior to the test, are more likely to disclose their diagnosis to their partner. Length of relationship, level of trust and honesty, and the level of communication within the relationship are just some of the other relationship factors that may influence disclosure. ${ }^{54}$

Recognising multiplicity of factors that inform whether an individual will disclose or not, multiple strategies that address these factors and that promote safe disclosure to a partner ought to be put in place. In sub-Saharan Africa PMTCT guidelines have placed undue burden of disclosure on the tested individual, an approach that has not resulted in satisfactory disclosure rates in many settings. An approach of redistributing the burden of disclosure from the women would theoretically enhance partner disclosure. Facilitated disclosure has a counsellor present during the testing process and they help with disclosure process in the post-testing period. The approach is favoured by HIV-infected couples as it facilitates disclosure, and, not entirely preventing adverse events from occurring, it does reduce adverse events. ${ }^{52}$ Couple testing is a widely used strategy that in addition to removing the burden of disclosure from the woman, it also provides a safe disclosure environment. Couple testing also enhances male partner support for uptake and adherence to PMTCT interventions. Another effective method that is safe and acceptable is couple testing within the comfort of the home. The counsellor is available to support the couple with mutual disclosure..$^{52}$ However, home-based testing may cause stigma consequent to erroneous disclosure to other family members. Finally, it is important to appreciate that gender and societal norms that bar women from having a voice may prevent women from disclosing their HIV-positive status. To address such factors, women's empowerment programmes and community-based programmes that address stigma associated with HIV can change norms related to gender and in so doing can facilitate positive status disclosure to partners. Support groups for infected women have also been shown to help women in their efforts towards disclosure.

The second important finding also not reported in any of the earlier studies is that involvement of the male partner is partly responsible for the association between nondisclosures of HIV status on MTCT. From previous studies, male involvement has been shown to determine uptake and compliance with PMTCT interventions such as antenatal clinic attendance, adherence to maternal and infant prophylaxis, uptake of appropriate feeding option and reduced number of missed appointments. ${ }^{21,22,28,34,55,56,57,58,59}$ Our study reports that only $18.3 \%$ of mothers had male partner involvement. The finding of $18.3 \%$ is similar to low rates found in previous studies conducted in Kenya and Tanzania (12.5\% and $16 \%$ respectively).$^{60}$ Barriers to male partner involvement have been classically divided into health system factors, socio-economic and cultural factors. Health system factors include long hospital waiting times, unfriendly staff and female-dominated services at the hospitals. Culturally antenatal matters have been left to the women and men who get involved have been viewed as being weak. Socioeconomic difficulties have discouraged men from getting involved because of time spent at the hospital could be used to work, and the double transport cost implications..$^{61,62}$ The low rate of male partner involvement in this study implies that HIV-positive mothers may lack the support and encouragement of their male partners. Strengthening male partner involvement has the dual effect of enhanced adherence to PMTCT interventions as well as presenting a safe avenue for disclosure of HIV status by removing the burden of disclosure from the woman. ${ }^{22}$

Several African countries have implemented programmes that work with men on various HIV-related issues. These programmes have demonstrated the importance of engaging men in an effort to boost women's uptake of PMTCT interventions. ${ }^{55}$ Men have been shown to support their involvement in PMTCT and antenatal clinic services. ${ }^{63}$ Strategies to enhance male partner involvement should empower women to have equal responsibility as well as fully participate in decision-making with regard to the health of the family. Health facilities can also support this role by initiating male-friendly services as well as offering services that are exclusively for men. Examples of innovative strategies to enhance male involvement include invitation of male partners to attend either prevention of mother-to-child transmission (PMTCT) or antenatal care (ANC) services using letters addressed to the male partner. ${ }^{60}$ Male involvement may also be enhanced by use of behaviour change as well as communication through the media. The aim of such approaches would be to try and change gender stereotypes as well as educate on involvement in PMTCT. Opinion leaders, such as village elders and pastors, have also been successfully used to deliver educational sessions on importance of male involvement and participation in PMTCT programmes.

\section{Limitations}

The findings from this research effort should be interpreted with the following limitations being considered. Firstly, the generalisability of the findings may be limited to settings with similar socio-demographic, cultural and economic characteristics. Another limitation that may have introduced social desirability bias is the nature of self-reporting for data collection. Self-reports predispose to bias as participants may attempt to present themselves in a perfect manner by lying about questions being asked. This study minimised that possibility by corroborating the reported findings as much as possible with patients' records, and assuring the respondents 
of data anonymity, privacy and confidentiality. Another limitation in the study owing to it being a retrospective study is recall bias. It is possible that mothers who had HIV-positive infants were better able to recall when they actually disclosed their HIV status as cases may have a better recall on past exposures than controls. Despite putting in measures to minimise risk of selection bias, facility-based studies are inherently flawed and make it possible that controls selected to represent the population may not be truly representative. In our case, it is possible that pregnant mothers who did not seek care at health facilities may differ from those who were being cared for at health facilities. Finally, mothers who were excluded from the study may have had positive healthseeking behaviours compared to those who were included, possibly introducing bias in the study.

\section{Conclusion}

Evidence from this study suggests an important relationship between failing to disclose HIV-positive status, non-inclusion of male partners' involvement and infant HIV acquisition. Given the important role played by socio-economic factors in PMTCT, stakeholders need to re-examine policies on disclosure and male partner involvement with a view to addressing the two behavioural contributors to MTCT. Evidence presented should invigorate stakeholders towards identifying and integrating effective methods that address safe disclosure. Additionally, the importance of male partner involvement as a strategy to increase HIV awareness as well as enhance disclosure should be adopted by all PMTCT care providers.

Finally, this study identifies and proposes areas for future research. Despite this study highlighting the associations between MTCT and behavioural variables, more studies need to address other behavioural factors not considered in this study. While we were able to establish that male partner involvement was partially responsible for the association observed between non-disclosure of male partner involvement to a partner and infant HIV acquisition, it is important to point out the simplistic nature of the model tested. More comprehensive mediation analysis on indirect association ought to be performed to fully decipher the complex relationship between MTCT and non-disclosure. A follow-up duplication study in an area with different socio-economic composition and cultural practices, as well as in a metropolitan area, to determine whether the association reported in this current study would hold should be performed.

\section{Acknowledgements}

This study was made possible by a study grant from the University of South Africa. The author would also like to thank the Department of Health, Siaya County, Kenya.

\section{Competing interests}

The authors declare that they have no financial or personal relationship(s) which may have inappropriately influenced them in writing this article.

\section{Authors' contributions}

All authors contributed extensively to this work. J.L.N. and G.V.R. conceptualised and designed the study. J.L.N. collected and analysed the data, and G.V.R. supervised the process. All authors discussed the results and implications and commented on the manuscript at all stages.

\section{References}

1. Panel on treatment of HIV-infected pregnant women and prevention of perinatal transmission. Recommendations for use of antiretroviral drugs in pregnant HIV-1infected women for maternal health and interventions to reduce perinatal HIV transmission in the United States [homepage on the Internet]. [cited 2017 Mar 08]. Available from http://aidsinfo.nih.gov/contentfiles/lvguidelines/PerinatalGL.pdf

2. World Health Organization. Consolidated guidelines on the use of antiretroviral drugs for treating and preventing HIV infection: Recommendations for a public health approach. Kuala Lumpur, Malaysia: WHO Press; 2013.

3. Frange $P$, Blanche $S$. Mother-to-child transmission (MTCT) of HIV. Press Medicale. 2014;43:691-697. https://doi.org/10.1016/j.lpm.2014.02.015

4. United Nations International Children's Emergency Fund (UNICEF). UNICEF Data: Monitoring the Situation of Children and Women [home page on the Internet]. 2016 [cited 2017 Mar 31]. Available from: https://data.unicef.org/topic/hivaids/emtct/

5. Nyandiko WM, Otieno-Nyunya B, Musick B, et al. Outcomes of HIV-exposed children in western Kenya: Efficacy of prevention of mother to child transmission in a resource-constrained setting. I Acquir Immune Defic Syndr. 2010:54:42-50. https://doi.org/10.1097/QAl.0b013e3181d8ad51

6. Kenya National AIDS and STI Control Programme. Kenya AIDS indicator survey 2012 Preliminary report. Nairobi: Government Printers; 2013.

7. United Nations Children's Fund. The state of the world's children. New York: UNICEF; 2008

8. National AIDS and STI Control Programme (NASCOP). Guidelines for prevention of mother to child transmission (PMTCT) of HIV/AIDS in Kenya. 4th ed. Nairobi Government Printers; 2015; p. 1-82.

9. Charurat M, Datong P, Matawal B, Ajene A, Blattner W, Abimiku A. Timing and determinants of mother-to-child transmission of HIV in Nigeria. Int J Gynecol
Obstet. 2009;106:8-13. https://doi.org/10.1016/j.ijgo.2009.02.017

10. Ahmad N. Molecular mechanisms of HIV-1 mother-to-child transmission and infection in neonatal target cells. Life Sci. 2011;88:980-986. https://doi.org/ 10.1016/j.lfs.2010.09.023

11. Brocklehurst P. Interventions for reducing the risk of mother-to-child transmission of HIV infection. Cochrane Database Syst Rev. 2002;CD000102. https://doi.org/ 10.1002/14651858.CD000102

12. Torpey K, Kabaso M, Weaver MA, et al. Infant feeding options, other nonchemoprophylactic factors, and mother-to-child transmission of HIV in Zambia. $J$ Int Assoc Physicians AIDS Care (Chic) [serial online]. Jan [cited 2014 Feb 28];11(1):26-33. Available from: http://www.ncbi.nlm.nih.gov/pubmed/21430237

13. The Independent Expert Panel. Prevention of mother-to-child transmission of HIV: Expert panel report and recommendations to the U.S. Congress and U.S. Global
AIDS Coordinator. Vol. 2013. [homepage on the Internet]. 2010 [cited 2017 May AIDS Coordinator. Vol. 2013. [homepage on the Internet]. 2010 [cited 2017 May
31]. Available from: https://www.pepfar.gov/documents/organization/135465.pdf

14. Delicio AM, Milanez $\mathrm{H}$, Amaral E, et al. Mother-to-child transmission of human immunodeficiency virus in aten years period. Reprod Health. 2011;8:35. https:// doi.org/10.1186/1742-4755-8-35

15. Koye DN, Zeleke BM. Mother-to-child transmission of HIV and its predictors among HIV-exposed infants at a PMTCT clinic in northwest Ethiopia. BMC Public Health. 2013;13:398-394. https://doi.org/10.1186/1471-2458-13-398

16. Baggaley R, Hensen B, Ajose $O$, et al. From caution to urgency: The evolution of HIV testing and counselling in Africa. Bull World Health Organ. 2012;90(9):633-712. https://doi.org/10.2471/BLT.11.100818

17. Suthar AB, Ford N, Bachanas PJ, et al. Towards universal voluntary HIV testing and counselling: A systematic review and meta-analysis of community-based approaches. Sansom SL, editor. PLoS Med. 2013;10(8):e1001496. https://doi. org/10.1371/journal.pmed.1001496

18. Ndege $S$, Washington $S$, Kaaria $A$, et al. HIV prevalence and antenatal care attendance among pregnant women in a large home-based HIV counseling and attendance among pregnant women in a large home-based HIV counseling and org/10.1371/journal.pone.0144618

19. Bachanas P, Medley A, Pals S, et al. Disclosure, knowledge of partner status, and condom use among HIV-positive patients attending clinical care in Tanzania, Kenya, and Namibia. AIDS Patient Care STDS. 2013;27(7):425-435. https://doi. org/10.1089/apc.2012.0388

20. Tam M, Amzel A, Phelps BR. Disclosure of HIV serostatus among pregnant and postpartum women in sub-Saharan Africa: A systematic review. AIDS Care. 2015;27(4):436-450. https://doi.org/10.1080/09540121.2014.997662

21. Aluisio A, Richardson BA, Bosire R, John-Stewart G, Mbori-Ngacha D, Farquhar C Male antenatal attendance and HIV testing are associated with decreased infant HIV infection and increased HIV-free survival. J Acquir Immune Defic Syndr. 2011;56(1):76-82. https://doi.org/10.1097/QAl.0b013e3181fdb4c4

22. Jasseron C, Mandelbrot L, Dollfus C, et al. Non-disclosure of a pregnant woman's HIV status to her partner is associated with non-optimal prevention of mother-tochild transmission. AIDS Behav. 2013;17(2):488-497. https://doi.org/10.1007/ s10461-011-0084-y 
23. Madiba S, Letsoalo R. HIV disclosure to partners and family among women enrolled in prevention of mother to child transmission of HIV program: enrolled in prevention of mother to child transmission of HIV program: Glob J Health Sci. 2013;5(4):1-13. https://doi.org/10.5539/gjhs.v5n4p1

24. Kibera PW. Impediments to facility delivery among HIV positive women in a Kenyan setting: Insights from women's accounts and the service delivery context. Diss Abstr Int Sect A Humanit Soc Sci. 2011;71(2):4567-4575.

25. Turan JM, Hatcher AH, Medema-Wijnveen JJ, et al. The role of HIV-related stigma in utilization of skilled childbirth services in rural Kenya: A prospective mixedmethods study. Bangsberg DR, editor. PLoS Med. 2012;9(8):e1001295.

26. Medley A, Garcia-Moreno C, McGill S, Maman S. Rates, barriers and outcomes of HIV serostatus disclosure among women in developing countries: Implications for prevention of mother-to-child transmission programmes. Bull World Health Organ. 2004;82(4):299-307.

27. Kiula ES, Damian DJ, Msuya SE. Predictors of HIV serostatus disclosure to partner among HIV-positive pregnant women in Morogoro, Tanzania. BMC Public Health. 2013;13:433. https://doi.org/10.1186/1471-2458-13-433

28. Roxby AC, Matemo D, Drake AL, et al. Pregnant women and disclosure to sexual partners after testing HIV-1-seropositive during antenatal care. AIDS Patient Care STDS. 2013;27(1):33-37. https://doi.org/10.1089/apc.2012.0327

29. Mucheto P, Chadambuka A, Shambira G, Tshimanga M, Gombe N, Nyamayaro W. Determinants of nondisclosure of HIV status among women attending the
prevention of mother to child transmission programme, Makonde district, prevention of mother to child transmission
Zimbabwe, 2009. Pan Afr Med J. 2011;8(1):51.

30. Igwegbe AO, Ugboaja JO. Rate and correlates of HIV serostatus disclosure among HIV positive pregnant women in Nnewi southeastern Nigeria. J Med Sci. 2010;1(7):296-301.

31. Udigwe GO, Mbachu II, Oguaka V, Onyegbule OA, Udegbunam O, Umeononihu OS. Pattern and predictors of partner disclosure of HIV status among HIV positive pregnant women in Nnewi Nigeria. Niger J Med J Natl Assoc Resid Dr Niger. 2013;22:336-340.

32. Reda AA, Biadgilign S, Deribe K, Deribew A. HIV-positive status disclosure among men and women receiving antiretroviral treatment in eastern Ethiopia. AIDS Care. 2012;25(8):1-5

33. Torpey K, Mandala J, Kasonde P, et al. Analysis of HIV early infant diagnosis data to estimate rates of perinatal HIV transmission in Zambia. PLoS One. 2012;7(8):e42859. https://doi.org/10.1371/journal.pone.0042859

34. Msuya SE, Mbizvo EM, Hussain A, Uriyo J, Sam NE, Stray-Pedersen B. Low male partner participation in antenatal HIV counselling and testing in northern Tanzania: Implications for preventive programs. AIDS Care. 2008;20(6):700-709. https://doi.org/10.1080/09540120701687059

35. Farquhar C, Kiarie JN, Richardson BA, et al. Antenatal couple counseling increases uptake of interventions to prevent HIV-1 transmission. J Acquir Immune Defic Syndr. 2004;37(5):1620-1626. https://doi.org/10.1097/00126334-200412150-00016

36. Seid M, Wasie B, Admassu M. Disclosure of HIV positive result to a sexual partner among adult clinical service users in Kemissie district, northeast Ethiopia. Afr Reprod Health. 2012;16(1):97-104.

37. Osinde MO, Kakaire O, Kaye DK. Factors associated with disclosure of HIV serostatus to sexual partners of patients receiving HIV care in Kabale, Uganda. Int J Gynaecol Obstet. 2012;118(1):61-64. https://doi.org/10.1016/j.ijgo.2012.02.008

38. Kebede D, Wassie L, Yismaw D, Kassaye KD, Lingerh W, Dejene Y. Determinants and outcomes of disclosing HIV-sero positive status to sexual partners among women in Mettu and Gore towns, Illubabor Zone southwest Ethiopia. Ethiop Heal Dev. 2005;19(2):126-131.

39. Olagbuji BN, Ezeanochie MC, Agholor KN, Olagbuji YW, Ande AB, Okonofua FE. Spousal disclosure of HIV serostatus among women attending antenatal care in urban Nigeria. J Obstet Gynaecol. 2011;31:486-488. https://doi.org/10.3109/014 43615.2011.563637

40. Stirratt MJ, Remien RH, Smith A, et al. The role of HIV serostatus disclosure in antiretroviral medication adherence. AIDS Behav. 2006;10(5):483-493. https:// doi.org/10.1007/s10461-006-9106-6

41. Bucagu M, Bizimana J, Muganda J, Humblet CP. Socio-economic, clinical and biological risk factors for mother-to-child transmission of HIV-1 in Muhima health centre (Rwanda): A prospective cohort study. Arch Public Health. 2013;71(1):4-16. https://doi.org/10.1186/0778-7367-71-4

42. Siaya County Health Management Team. Siaya County HIV and AIDS strategic plan 2016-2019. Nairobi: Government printers; 2017

43. Office of the AIDS Advisory Council. Guidelines for the use of antiretroviral agents in HIV-1-infected adults and adolescents. Bethesda, MD: OARAC, 2012 pp. 1-334.
44. Schulz KF, Grimes DA. Epidemiology series Case-control studies: Research in reverse. Lancet. 2002;359(9304):431-434. https://doi.org/10.1016/S0140-6736(02)07605-5

45. Kim MY, Xue X, Du Y. Approaches for calculating power for case-cohort studies. Biometrics. 2006;62(3):929-933. https://doi.org/10.1111/j.1541-0420.2006. 00639_1.x

46. Ghasemi A, Zahediasl S. Normality tests for statistical analysis: A guide for nonstatisticians. Int J Endocrinol Metab. 2012;10(2):486-489. https://doi.org/ 10.5812/ijem.3505

47. Kenny DA. 2001. Mediation [homepage on the Internet]. [cited 2016 May 14]. Available from: http://davidakenny.net/cm/mediate.htm

48. Preacher KJ, Leonardelli GJ. 2001. Calculation for the Sobel test [homepage on the Internet]. [cited 2016 June 07]. Available from: http://www.unc.edu/ preacher/ sobel/sobel.htm

49. Baruch Y. Response rate in academic studies - A comparative analysis. Hum Relat. 1999;52(4):421-438. https://doi.org/10.1177/001872679905200401

50. Choung RS, Locke GR, Schleck CD, et al. A low response rate does not necessarily indicate non-response bias in gastroenterology survey research: A populationbased study. J Public Health (Germany). 2013;21:87-95. https://doi.org/10.1007/ s10389-012-0513-z

51. Bjertness E, Sagatun A, Green K, Lien L, Søgaard AJ, Selmer R. Response rates and selection problems, with emphasis on mental health variables and DNA sampling in large population-based, cross-sectional and longitudinal studies of adolescents in Norway. Biomed Cent Public Health. 2010;10(1):602-616. https://doi. org/10.1186/1471-2458-10-602

52. Walcott MM, Hatcher AM, Kwena Z, Turan JM. Facilitating HIV status disclosure for pregnant women and partners in rural Kenya: A qualitative study. BMC Public Health [serial online]. 2013 Jan [cited 2014 Feb 28];13:1115. Available from: http://www.pubmedcentral.nih.gov/articlerender.fcgi?artid=3907031\&tool=pmc entrez\&rendertype=abstract

53. Maman SMA. Gender dimensions of HIV status disclosure to sexual partners: Rates, barriers and outcomes. WHO Press: Geneva, Switzerland; 2011.

54. Makin JD, Forsyth BWC, Visser MJ, Sikkema KJ, Neufeld S, Jeffery B. Factors affecting disclosure in South African HIV-positive pregnant women. AIDS Patien Care STDS. 2008 Nov;22(11):907-916. https://doi.org/10.1089/apc.2007.0194

55. Kalembo FW, Zgambo M, Mulaga AN, Yukai D, Ahmed NI. Association between male partner involvement and the uptake of prevention of mother-to-child transmission of HIV (PMTCT) interventions in Mwanza district, Malawi: A retrospective cohort study. Kissinger P, editor. PLoS One. 2013;8(6):e66517.

56. Nyondo A, Chimwaza A, Muula A. Exploring the relevance of male involvement in the prevention of mother to child transmission of HIV services in Blantyre, Malawi. BMC Int Health Hum Rights. 2014;14(1):30-42. https://doi.org/10.1186/ s12914-014-0030-y

57. Bii SC, Otieno-Nyunya B, Siika A, Rotich JK. Infant feeding practices among HIV infected women receiving prevention of mother-to-child transmission services at Kitale District Hospital, Kenya. East Afr Med J. 2008;85(4):156-161. https://doi. org/10.4314/eamj.v85i4.9639

58. Laher F, Cescon A, Lazarus E, et al. Conversations with mothers: Exploring reasons for prevention of mother-to-child transmission (PMTCT) failures in the era of programmatic scale-up in Soweto, South Africa. AIDS and Behav. 2012;16:91-98. https://doi.org/10.1007/s10461-010-9875-9

59. Varga CA, Sherman GG, Jones SA. HIV-disclosure in the context of vertical transmission: HIV-positive mothers in Johannesburg, South Africa. AIDS Care. 2006;18(8):952-960. https://doi.org/10.1080/09540120500356906

60. Byamugisha R, Tumwine JK, Ndeezi G, Karamagi CAS, Tylleskär T. Attitudes to routine HIV counselling and testing, and knowledge about prevention of mother to child transmission of HIV in eastern Uganda: A cross-sectional survey among antenatal attendees. J Int AIDS Soc. 2010;13(1):52-57. https://doi.org/10.1186/ 1758-2652-13-52

61. Byamugisha R, Tumwine JK, Semiyaga N, Tylleskär T. Determinants of male involvement in the prevention of mother-to-child transmission of HIV programme in Eastern Uganda: A cross-sectional survey. Reprod Health [serial online]. 2010 Jun 23 [cited 2017 Apr 8];7:12. Available from: http://www.ncbi.nlm.nih.gov/ pubmed/20573250

62. Makoni A, Chemhuru M, Chimbetete $C$, et al. Factors associated with male involvement in the prevention of mother to child transmission of HIV, Midlands Province, Zimbabwe, 2015 - A case control study. BMC Public Health [serial online]. 2016 Apr 14 [cited 2017 Apr 8];16:331. Available from: http://www.ncbi. nlm.nih.gov/pubmed/27079659

63. Theuring S, Mbezi P, Luvanda H, Jordan-Harder B, Kunz A, Harms G. Male involvement in PMTCT services in Mbeya Region, Tanzania. AIDS Behav. 2009;13(Suppl 1):92-102. https://doi.org/10.1007/s10461-009-9543-0 